\title{
Narrative Ethics and the Ecology of Culture: Notes on New Italian-Icelandic Sagas
}

\section{Antonio Casado da Rocha}

The following are a few loose notes about a tough subject: the relationship between ethics, storytelling and the legal-cum-social framework that makes human creativity thrive or decay. Rather than a tight argument, what I propose here is a few, unoriginal hints, in the hope that they may help others to pursue a fuller answer to the question, On what depends the preservation of transmission of a culture? Using some thoughts by A. MacIntyre and some examples taken from the history of Icelandic literature, I emphasize the role of alternative ways of understanding intellectual property, as well as some contemporary experiments in mythopoiesis, such as the one by the Italian collective of writers-activists known as Wu Ming.

\section{Italian Storytellers of the Internet Age}

Of all the beginnings of an ethics book, one of the most famous, and rightly so, is that of MacIntyre's After Virtue:

"Imagine that the natural sciences were to suffer the effects of a catastrophe. A series of environmental disasters are blamed by the general public on the scientists. Widespread riots occur, laboratories are burnt down, physicists are lynched, books and instruments are destroyed. Finally a Know-Nothing political movement takes power and successfully abolishes science teaching in schools and universities, imprisoning and executing the remaining scientists. Later still there is a reaction against this destructive movement and enlightened people seek to revive science, although they have largely forgotten what it was. But all that they possess are fragments: a knowledge of experiments detached from any knowledge of the theoretical context which gave them significance; parts of theories unrelated either to the other bits and pieces of theory which they possess or to experiment; instruments whose use has been forgotten; half-chapters from books, single pages from articles, not always fully legible because torn and charred. Nonetheless all these fragments are reembodied in a set of practices which go under the revived names of physics, chemistry and biology. Adults argue with each other about the respective merits of relativity theory, evolutionary theory and phlogiston theory, although they possess only a very partial knowledge of each. Children learn by heart the surviving portions of the periodic table and recite as incantations some of the theorems of Euclid. Nobody, or almost nobody, realizes that what they are doing is not natural science in any proper sense at all. For everything that they do and say conforms to certain canons of consistency and coherence and those contexts which would be needed to make sense of what they are doing have been lost, perhaps irretrievably."(MacIntyre 1984)

After this allegory of a world where all sciences have been dismantled, MacIntyre advances the hypothesis that in the actual world the language of morality is in the same state of grave disorder as the language of science in the imaginary 
world which he described. Specifically, MacIntyre applies this hypothesis to advance the notion that the ethical theories that emerged from the Enlightenment were philosophically doomed from the start because they were formed using the aforementioned incoherent language of morality.

This is a fascinating hypothesis, but I want to focus more on the allegory itself, imagine ways in which it can become true. MacIntyre knew well that this situation of a future without a past has been described by many science-fiction writers. One of the most recent ones is Ursula $\mathrm{K}$. LeGuin in her novel The Telling: On the planet Aka there rules the dictatorship of a state-enterprise ("the Corporation") which has tried to destroy all pre-existent histories and myths. Some communities resist and turn to thousands of subterfuges in order to continuing telling histories. "The Telling" is precisely the name of this religion, a cult of storytelling without super-natural entities. At one point, a shaman-storyteller affirms that not only war and exploitation but pollution and ecological crisis also are consequences of a great perturbation in the transmission of stories:

"without the telling, the rocks and plants and animals go on all right. But the people don't. [...] But all we know is how to learn. How to study, how to listen, how to talk, how to tell. If we don't tell the world, we don't know the world. We're lost in it, we die. But we have to tell it right, tell it truly. That's what went wrong [...] Telling people that nobody knew the truth but them, nobody could speak but them, everybody had to tell the same lies they told. Traitors, usurers! Leading people astray for money! Getting rich off their lies, bossing people! No wonder the world stopped going around! No wonder the police took over!" (LeGuin 2000)

The Italian collective of writers that anonymously signs as "Wu Ming" sees this problem as an interference caused by the logic of capitalism: in the name of an eternal present of production and consumption, capitalism impedes the transmission of culture and memory to our descendents. Wu Ming shares LeGuin's solution: the problem can only be resolved through story-telling and copying, copying and storytelling, making stories circulate, and removing any obstacle to this circulation. But there are three different kind of obstacles for this solution (Ming 2003):

1. The perishability of the materials. From the Palaeolithic onwards, the vulnerability of information platforms has not ceased increasing. Cave designs, fixed in bare rock, have survived fifteen thousand years. Many documents written on papyrus and on vellum exist, and are still legible and restorable. The paper used until the end of 1870 is yellowing but preserved. By contrast, the cellulose paper manufactured from the end of the 19th century until today consumes itself due to the acids that it contains. Following existing calculations, already twenty five percent of books dating from post-1870 preserved in the libraries of the world have been destroyed.

2. The obsolescence of the information platforms and technologies. Some wax phonograph cylinders, though deteriorated, would still be listenable, but there are no phonographs left. The sound of magnetic tapes little by little become more quiet and tenuous, and often there is no longer any way to read them, as happened with the old 8 track tapes. The development of hardware and software burns every bridge it crosses. For instance, we have already lost an indeterminate quantity of the data kept on 5.25 inch diskettes, because we have scrapped the computers that could read 
them. In addition, as we have pushed numerous species of software to "extinction," the information stored in those programs is no longer readable.

3. Intellectual property, the defence of which prohibits copying. But copying is a solution to the two previous problems and, if we think about it, it has always been. In order to avoid perishability and obsolescence, human beings have constantly performed "migrations" of texts from one book to another book, "refreshing" documents from one platform to the other, from hand-writing to the printing press.

\section{Sagas, Science and Commons}

We have been doing this constant copying for a long while. As soon as the Icelandic sagas were first written on vellum in the 13th and 14th century, enthusiastic readers began to copy them and re-write for their own use and for further distribution. The tradition of copying and circulating manuscripts remained unbroken from the beginning of saga-writing in the middle ages beyond the development of printing technique in 16th century and all the way up to modern times. The immense number of manuscripts, preserved in national and local archives throughout Iceland, clearly indicates how people used their writing skills for communication and creation, collection and distribution. The vaults are filled with handwritten books, production and reproduction of literary and scholarly material such as traditional poetry and prose, rhymes, sagas and folktales, history and genealogy. Manuscripts were written, rewritten and copied, and sometimes printed books were copied in the same manner and distributed as handwritten books. Important part of this manuscript culture, which we can call the peoples' press, is the copy and distribution of Icelandic medieval literature, stories of warriors and wise men, poets and politicians of the golden age of settlement and commonwealth. (Ólafsson 2002)

Here the problems of copyright and intellectual property reappear. According to present copyright law, the "peoples' press" would be hardly legal. But copyright law also presents one problem, one related to the sciences' dependency upon the ability to observe, learn from, and test the work of others. Without effective access to data, materials and publications, the scientific enterprise becomes impossible. Yet recent studies show a disturbing trend; increasing secrecy, cumbersome materials transfer agreements and complex licensing structures have made more difficult the sharing process on which science relies. "Because they were denied access to data, $28 \%$ of geneticists reported that they had been unable to confirm published research," a recent article in the Journal of the American Medical Association reports. (Campbell, Clarridge et al. 2002)

Unlike natural resources, information and other "intangible goods" can be treated as part of "the commons"-resources that are not divided into individual bits of property but rather are jointly held so that anyone may use them without special permission. This kind of resources or "social goods" is special because, once created, they cannot be depleted. In the words of Thomas Jefferson, "He who receives an idea from me, receives instruction himself without lessening mine; as he who lights his taper at mine receives light without darkening me."

As Lawrence Lessig (2004) aptly explains it, too often the debate over the control of information tends to the extremes. At one pole is a vision of total control-a world in which every last use of information is regulated and in which "all rights 
reserved" is the norm. At the other end is a vision of anarchy-a world in which information enjoys a wide range of freedom but is left vulnerable to exploitation. In order to restore balance, compromise, and moderation-once the driving forces of a copyright system that valued innovation and protection equally-, the non-profit organization Creative Commons uses private rights to create public goods, in order to offer a best-of-both-worlds way to protect certain goods while encouraging certain uses of them-to declare "some rights reserved".

Recently, Creative Commons have brought their goal-to build a layer of reasonable, flexible copyright in the face of increasingly restrictive default rules-to the realm of science by launching the Science Commons project. Its mission is to encourage scientific innovation by making it easier for scientists, universities, and industries to use literature, data, and other scientific intellectual property and to share their knowledge with others. Science Commons works within current copyright and patent law to promote legal and technical mechanisms that remove barriers to sharing. So instead of extending restrictive copyrights to databases, by using creative/science commons licences we could both assure broad access to scientific data within a legal background that might give everyone their due, thus achieving a more just sharing of benefits.

\section{Sagas and Narrative Ethics}

Let's go back to MacIntyre. In After Virtue, he also argued that one can only answer the moral question "What am I to do?" if one can answer the prior question "Of what story or stories do I find myself a part?" Although there are important differences among scholars regarding not only what kind of moral work stories are supposed to do, but also on what they imply about the nature of morality in general, anyone adopting a narrative approach to ethics must answer at least the question, What is done with the story? There are at least three possible answers.

The first one is that we use stories as a vehicle for our ethics. Narrative is then seen as education in moral practice, as a subtle evaluative classification that tells us how our culture discriminates actions (some are good, some are bad, others are indifferent, and so on). What are learned by means of those stories are not simply some facts; what are learned are values. Stories thus provide a structure which gives moral meaning to the particulars of a given experience or situation.

A second answer sees narrative as an adequate methodology in moral theory and practice. The point here is not only that we actually learn through stories, but also that using stories is the best way to understand and improve our ethics. Of course, what we learn through stories cannot be reduced to the sentences that are given to children as the story's moral. In her writings on philosophy and literature, Martha Nussbaum has linked the significance of literary texts in moral education to a procedure that begins with the question, "How should a human being live?" According to Nussbaum, a good way to answer this question is by starting an inquiry, which works through the major moral positions looking for what lies deepest in human life. Literature plays at least two functions in this ethical inquiry. First, thanks to narrative "we get a sufficiently rich and inclusive conception of the opening question and of the dialectical procedure that pursues it-inclusive enough to hold all that our sense of life urges us to consider." (Nussbaum 1992)26) Second, she argues that such an inclusive conception of ethics requires forms and structures that we can 
only find in select literary works. Those books are not ethically neutral, because built into their structure is a conception of what matters. By consenting to see the events in the story as the author presents them, not only readers implicitly break with moral nihilism-with any theory whose outcome is that everything matters the same, and therefore, that nothing matters at all-, they also learn to see the world in a whole new way.

A third possible answer to my initial question about narrative ethics has to do with justification. Its least controversial version asserts that an ethic of principles must be supplemented by an understanding of the narrative structure of human action. There are three reasons for this assertion: first, because narrative elements such as examples or parables are pervasive in all forms of ethical reasoning (as in the above quoted allegory by MacIntyre); second, because our responses to stories are the ground out of which principles and theories grow; and third, because narrative is the only medium in which a concern for virtue can be intelligibly discussed.

This is especially clear in the Icelandic sagas. Typically, the narrative of a saga proceeds as "a series of killings with its action structured by the duty to exact revenge for death or for offence inflicted on oneself, a friend, or a family member. This pattern is shot through with ethical threads because fundamental values and interests are at stake for both individuals and the community." (Árnason 19991:157) Vilhjálmur Árnason concludes that the moral structure of the sagas cannot be understood without reference to the social structure of Icelandic Free State, and that this society cannot be analyzed without the moral virtues that enable individuals to carry out their roles. The moral drama of the Icelandic sagas is thus based on the conflict between the social need for peace and the heroic morality of honour and personal integrity. (Árnason 1991:174)

Sagas can be seen as an ancient form of today's "crime journalism". In both cases, it can be argued that crime stories define a society's morals, what is true and correct, what is perceived as normal and deviant, what is permissible and what is forbidden. "Different actors, social institutions and interest groups participate in the struggle over definitional power in these areas. Viewed in this way, the crime journalism of a given epoch manifests those social problems and threats that are perceived to be most important and the ongoing cultural conflicts of each historical period can be traced in the crime reporting of the time. One might perhaps argue that one of the many possible roles assumed by crime reporting is that of the modern myth, which serves to establish the limits of social life." (Kleberg and Pollack 2005)

Those limits are always open to further question. The answer to the question "why" about a decision, what we call its "justification," is always both retrospective and anticipatory. As Páll Skúlason writes, "Through the motives, both the past (remembered) and the future (anticipated) appear in the present as a process of unifying experience and action, thought and will, at a crucial moment of a saga which has to be written into the world". This is why neurotic and depressed people lose their sense of time: they are not able to make an intelligible story out of their lives; the past is in chaos, there is no future, and the living present is dissolved and meaningless; their lives have, so to speak, stopped, and yet they are still alive, suffering this impossible "ending" (Skúlason 1999:20).

The moral question, both in its particular version (What should I do?) and in the general one (What is the good life?) does not take place in a vacuum; it takes 
place in a situation, in the mare magnum of our everyday lives. To answer the question we have to look at the concrete situation where it takes place. But what is it to be in a situation? To understand that, we have to look at real or fictitious situations-that is what philosophers have always being doing. Skúlason points out the fact that "each time we try to view a situation, we do so by telling a story about what is going on". Thus he claims that "a human situation is only to be understood as a segment of a saga where the historical dimensions of experience and of action are brought to light." (1999:19)

\section{Conclusion: Towards an Ecology of Culture}

However tentatively, I have suggested that (i) we need copying to preserve our stories and (ii) we need stories for our ethics. If this is correct, then we have a need for an "ecology of culture," devoted to something more than understanding and preserving of our biosphere. Since humans live not only in a biological environment, but also in an environment that was created by one's ancestors and by oneself, preservation of this cultural environment is as important a task as is the preservation of nature.

The ecology of culture needs the constant retelling of stories for political reasons. In "Myth and Ideology," Flood seeks to articulate a model of what he calls "political myths," narratives that carry a specific political ideology and so invite their audience to assent and potentially to act in accordance with it. He develops his model of political myths so as to provide a tool for identifying and analyzing both the political dimension of mythic discourse and the mythic dimension of political discourse. He argues against the irrationalist tradition in political theory that holds that mythic beliefs are symptoms of an emotionally driven, collective, psychological need to believe that overrides rational knowledge or evaluation of evidence. (Schilbrack 2002)

Rather, mythmaking seems to be an everyday practice which permeates the discourse of political communicators. As Flood puts it, mythmaking "is an entirely normal way of making political events intelligible in the light of ideological beliefs. Some stories acquire importance within a social group over a long span of time. Others have only the most ephemeral currency. But the production and the reproduction of mythopoeic narratives are constant features of political life." (Flood 2002)

No contemporary group of writers is more aware of this than Wu Ming. Theirs is the last word:

"Our stance on the Italian social movements stems from that: we are interested in mythopoiesis, i.e. the social process of constructing myths, by which we do not mean 'false stories,' we mean stories that are told and shared, re-told and manipulated, by a vast and multifarious community, stories that may give shape to some kind of ritual, some sense of continuity between what we do and what other people did in the past. A tradition. [...] Myths are necessary. We couldn't live together without stories to tell and listen to, without 'heroes' whose example we can follow or reject. Our language, our memories, our imagination and our need of forming communities are the things that make us human beings, and the stories keep them all together. [...] As far as this kind of experimentation (radical 'mythopoiesis') is concerned, Italy's always been an exciting laboratory. For many historical and social reasons, the Italian social movements were able to emerge as multitudes of people describing themselves by an 
endless, lively flow of tales, using those tales as weapons in order to impose a new imagery from the grassroots." (Ming 2002)

\section{References}

Árnason, V. (1991). "Morality and Social Structure in the Icelandic Sagas." Journal of English and Germanic Philology 90(2): 157-174.

Campbell, E. G., B. R. Clarridge, et al. (2002). "Data Withholding in Academic Genetics: Evidence From a National Survey." JAMA (287): 473-480.

Flood, C. (2002). Myth and ideology in Thinking Through Myths: Philosophical Perspectives. K. Schilbrack. London, Routledge: 174-190.

Kleberg, M. and E. Pollack (2005). Media stories: murder, motives and moralities. 4th Media in Transition conference. Cambridge, MA, MIT. Lessig, L. (2004). Free Culture: How Big Media Uses Technology and the Law to Lock Down Culture and Control Creativity. New York, Penguin.

MacIntyre, A. (1984). After Virtue: A Study in Moral Theory. Notre Dame, Indiana, University of Notre Dame Press.

Ming, W. (2003). "Better Than Gingko Biloba: The struggle against copyright improves memory." Retrieved November 12, 2005, from

http://www.wumingfoundation.com/italiano/outtakes/gingko english.htm.

Nussbaum, M. C. (1992). Love's Knowledge: Essays on Philosophy and Literature. New York, Oxford University Press.

Ólafsson, D. (2002). "Sagas in handwritten and printed books in 19th century Iceland." Retrieved December 12, 2005, from http://w210.ub.unituebingen.de/dbt/volltexte/2004/1065/.

Schilbrack, K. (2002). Introduction: on the use of philosophy in the study of myths. Thinking Through Myths: Philosophical Perspectives. K. Schilbrack. London, Routledge: 1-17. 